\title{
JAPANESE STUDIES IN VERBAL LEARNING AND MEMORY
}

\author{
TAKAO UMEMOTO \\ Kyoto University
}

\begin{abstract}
It is regrettable that many Japanese works in verbal learning and memory have been almost unknown to American and European psychologists because of the language barrier. Since the Japanese Journal of Psychology was published in 1927, more than two hundred experiments have been done in this field. Although the number of papers is not so great as those in the field of perception as reviewed by Prof. Akishige (3) in this journal, many unique and interesting studies have appeared. While it was impossible to criticize all the data in this short paper, the author has attempted to review only those works dealing with several typical problems, such as retroactive inhibition, transfer, change of trace, incidental learning, spread of effect and paired associates learning. Of course there are many other studies working on the problems of developmental factors, association, semantics, problem solving, resumption of interrupted tasks and so on. The author hopes that those studies will be reviewed by someone at an early day.
\end{abstract}

\section{Change of Trace}

It was in 1922 that Wulf (110) conducted experiments on the change of memory trace. He shows that the direction of change in memory trace is always ruled out by the Gestalt law of pregnance. There are three main tendencies in the change of figure trace noted by Wulf: leveling, sharpening and normalizing. Gibson (14) supported, in 1929, Wulf's results and explained these tendencies in terms of "object assinilation, verbal analysis and figure assimilation." But today all psychologists may know that this phenomenon is not simply considered as "change of memory trace" but rather as a modification of figures by "expression." After 1937 many negative data had appeared, such as experiments of Irwin and Seidenfeld (1937), Irwin and Rovner (1937), Seidenfeld (1938), Goldmeier (1941), Hanawalt and Post (1942), Tennies (1942), Hebb and Foord (1946) and Hanawalt (1952). Strangely enough the first negative experiment by a Japanese psychologist is scarcely known. In 1930, Amano $(4,5,6)$ made a series of experiments on the perception and recall of figures. In his first experiment, nine simple nonsense figures were presented to five subjects. Recall test by drawing was done after 30 sec., $30 \mathrm{~min} ., 24 \mathrm{hrs}$. and 60 days. Result was that the difference between original stimulus figures and reproduced figures had no consistent tendencies; it differed for each subject and for each figure. Moreover the direction of change of figures appeared in the first recall was not always maintained in later recall. But the difference of reproduced figures was more remarkable between the first recall (after $30 \mathrm{sec}$.) and second recall (after $30 \mathrm{~min}$.) than the second recall and third recall (after $24 \mathrm{hrs}$.). The length of exposure time $(1 \mathrm{sec} ., 3 \mathrm{sec}$. and $10 \mathrm{sec}$.) had no influence upon the change of reproduced figures. In the second experiment the stimulus figures were presented three times in order that subjects memorized it more perfectly. But the results showed in recall after $24 \mathrm{hrs}$. and after 30 days were the same as in the first experiment. Amano pointed out, in discussion, that there were three iniplicit and faulty hypotheses in Wulf's assertion, that is, (1) identity between stimulus figure and perceived figure, (2) coincidence between memory trace and reproduced figure and (3) no influence of interpolated reproduction upon memory trace. From above data he concluded that Wulf's generalization on the change of trace was only an arbitrary interpretation by the experimenter 
about the difference between stimulus figure and reproduced figure. While these changes included the modification due to drawing performance, reproduction method should not be used as a valid method to measure the change of trace. He said there could not be found any other change in memory trace than "progressive obscuring."

In about twenty years after Amano's experiment, Abe $(1,2)$ again took up the problem. He made similar experiments as Amano's but with the method of reproduction and recognition. Time intervals between original presentation and recall trials were $30 \mathrm{sec}$., one day, 4 days and two weeks. He found only twenty percent of reproduced figures showed progressive change, which followed the Gestalt law of pregnance (1, p.37, Table 1). Comparing the structural characteristics of the recognized figure with that of reproduced figure in successive recall, he found two kinds of figure changes. One is the positive change in which the directions of change in recognition and reproduction are same, and another is the negative change in which the directions of changes in recognition and reproduction are contradictory. More positive changes occured with difficult and ambiguous figures and more negative changes occured with easy and stable figures (1, Table 7). Moreover positive changes appeared more frequently in recall and recognition after two weeks than immediately after (2, Table 12). These results were interpreted by him that when original stimulus figures were more stable and better retained, the difference between recognized figure and reproduced figure would be great. When the original stimulus figures were more unstable and poorly retained, subject's memory traces were so much influenced by the reproduced figures that he might choose in recognition test these which were more similar to the frgure drawn by himself (2, p. 35).

The subjects of these experiments of Amano and Abe were all adults. What kind of results will be obtained by the use of children as subjects? The experiments of Yamashita and Nakajima (111), Komatsu (46), Onishi (76), and Katsui and Obonai (40) were all done with children. The purpose of the experiment of Katsui and Obonai was to examine the Hebb's results (21). Children of 3 to 7 years learned stimulus figures-angle and arc-to one perfect trial. Recognition test was made immediately or 24 hrs. after. Results confirmed Hebb's assertion and again Wulf's hypothesis was denied. But in their experiment, there was a tendency to over-estimate the larger angles and under-estimate the snall angles in recognition $\mathbf{3 8}$, p.356, Table 4). They explained this phenomenon in terms of "absolute impression."

\section{Retroactive Inhibition, Transfer and Isolation EfFect}

It seems that the Japanese psychologist before the Second World War had been rather more influenced by German psychological works than American ones. So almost all the early works on retroactive inhibition were done as the critique or extention of Gestalt studies in memory, such as the works of Köhler and Restorff (46) and I. Müller (73).

Yatabe (112), in 1935, reviewed all the data in retroactive, proactive and Ranschburg's inhibition for the first time in Japan. His historical review and critique was so excellent that it became a guide book for Japanese psychologists in this region for a long time.

The first experiment in retroactive inhibition was done by Sagara (82) in 1936. There were six conditions in which two original lists (OL) and three interpolated lists (IL) were used as materials. One of the OL was composed of four pairs of colors and four pairs of 
numbers. The other was composed of four pairs of color words and four pairs of two place number. Each of IL was composed of either 8 items of color (list 1), 8 items of color words (list 2) or 8 items of number (list 3). Results shown in correct response were that the amount of RI was the greatest when OL and IL were composed of same materials (80, p. 127, Table 1). In his second experiment, he made OL and IL with color, color name-both presented visually -and color name auditory presented. As same as the first experiment, results showed that RI was greater when the material and mode of presentation of OL and IL were the same rather than different (ibid. p. 128). When the materials of OL and IL were figures or name of figures(such as triangle, circle, square, etc.), in his third experiment, results also confirmed the above generalization (p. 133). The fourth experiment is unique one. One original list consists of 4 pairs of two place number, 2 pairs of alphabet and 2 critical pairs. The other original list also consists of 4 pairs of two place number, 2 pairs of figures and 2 critical pairs. The critical pairs, which were same in both OLs, were made so ambiguous that one could perceive it either as. alphabet or figure. Interpolated lists consists of (1) 8 items of alphabet, (2) 8 items of figure and (3) 8 items of number. The following results were obtained (p. 136). When the critical pairs were members of the figure lists, they were recalled better in the condition in which the IL was alphabet or numbers. When the critical pairs were members of alphabet list, they were recalled better in the condition in which the IL was composed of figures or numbers. It means that even when there are same original (critical) pairs and same ILs in two conditions, the difference in the material of the irrelevant original list causes different inhibiting effects. We might regard the problem of this experiment, from the more up-to-date point of view, as dealing with the analysis of intra-list similarity through retroactive inhibition (RI).

Fujita's experiment (13) (1938) is not on RI but rather on the isolation effect. He showed for the first time that the isolation effect was found also in the conceptual level. For instance, when a family name was inserted in the twenty items of city-names, it was recalled $100 \%$ after twice presentation while the city-names were recalled only $55 \%$ in average. But when nonsense syllables were isolated in the list of meaningful words, they were not recalled so often. When crowded, meaningful words were all the name of birds, the amount of recall was $42.9 \%$ for isolated nonsense syllable and $77.1 \%$ for names of birds, while when crowded, meaningful words consisted of various nouns, it was $71.4 \%$ and $65.0 \%$ respectively.

Takemasa and Hashimoto (92) in 1938 also supported the Gestalt explanation of RI and PI (proactive inhibition) by the principle of crowding. In their experiment, the number of prior lists or interpolated lists in PI and RI conditions were two, three of four. Original list was composed of syllables, figures and numbers. The results were that when IL also was composed of various kind of materials the amount of RI was great, and when IL was composed of one kind of material, the amount of RI was small.

In 1939, again, Sagara (83) made two unique experiments on retroactive inhibition and intra-list similarity. In his experiment three OLs were made, each of which was composed of two kinds of materials: letters and figures, or figures in fine lines and thick lines, or technical terms and popular terms. Five kinds of IL are made; the items in IL 1 were color; IL 2 and IL 3 were each composed of one kind of material which was the same component of OL; IL 4 was composed of the same two kinds of materials as in OL; IL 5, the critical list, was compos- 
ed of a material which had a medium character of two materials in OL. For instance, ornamental initial was assumed to have a medium character of letter and figure. The result was that the amount of retroactive inhibition was great in the condition in which the critical list was interpolated. When color list was interpolated, there was only little RI, and when list 2,3 and 4 were interpolated, a considerable amount of RI were found. Sagara interpreted these results that the original list which was differentiated into two regions at the time of original learning was mediated by the IL 5 which had a medium character to both material of OL, and the two regions of OL were fused and assimilated reciprocally (81, p. 17). In his second experiment, the same hypothesis was supported in the intra-serial condition. When a list was composed of two different materials and one mediation material, intra-list inhibition was progressively severe in proportion to amount of mediation materials. (The total amount of items were 20 , and mediation items were 4,6 or 8 ). Moreover the effects of mediation items upon the rate of recall were greater when serial position of items was in the anterior part of the list than in the posterior.

These experiments which have been described above were all designed to analize the similarity factor of RI and PI. But in 1940 the first experiment on the temporal factor was done by Maeda (59). After having confirmed the results of I. Müller (73), who showed RI was greater when IL were interpolated before the relcarning trial than immediately after. OL. he made an experiment in which the time intervals between IL and $\mathrm{RL}$ were varied. The hypothesis was that if RI was caused only by retroaction effect of IL, the amount of RI would be greater when the time interval between IL and RL was prolonged. The time intervals between IL and RL were 0,15 or $30 \mathrm{~min}$., and between OL and IL were $15 \mathrm{~min}$. Lists were all composed of syllables, figures and numbers. The results did not confirm the above hypothesis, that is the percentage of correct recall was the best when the time interval between IL and RL was 15 min., and the next was the condition in which RL was held immediately after IL, and the $30 \mathrm{~min}$. interval condition was the worst for correct recall. In his next experiment the time intervals between OL and IL were varied in both RI and PI design. As a result in PI condition, the longer the time interval between prior list and OL the smaller the amount of PI. But in RI condition, percentage of correct recall increased gradually until the time interval between $\mathrm{OL}$ and IL was 15 min., and then decreased. He interpreted these results in terms of the "filter effect of IL" (I. Müller) (73).

It is generally known that Melton and von Lackum (65) found out that the amount of RI was greater than the amount of PI and established the two factor theory of RI in 1941. But Maeda, in 1940, already had found this fact as a result of his experiments. In his experiment OL was made with 2 syllables, 2 figures and five two-place numbers. There were two ILs or disturbing lists with (A) 6 syllables and 3 numbers and (B) 6 figures and 3 numbers. In condition 1, three lists were learned in the sequence of list $A-O L-$ list $B$, and in the other conition in the sequence of list $B-O L-$ list $A$. Results showed that, in condition 1, the percentage of correct recalled items of OL was greater in syllables than figures, while in the other condition figures were more often recalled. It is obvious from these results that the amount of RI is greater than that of PI. He further analyzed these results and made a conclusion that the main mechanisms of filter effect of IL were considered to be the distur'. ing of the recall process of OL 
and as the absorbing the similar items from OL. (58, p. 280)

After Maeda's experiment in 1940, no works on RI appeared during the Second World War. In 1948 Umemoto (100) did a series of experiments on RI and associative inhibition. The problem posed was to find out the difference between RIs caused by different kinds of materials. The finding was that although OL and IL were similar, the amount of RI was the smallest when both OL and IL were composed of two place numbers. When they were composed of nonsense syllables or figures, the amount of RI was much greater. In his second experiment, one group of subjects learned OL and IL both composed of familiar city-names, and the other group learned OL and IL of unfamiliar city-names. The criteria of original learning and interpolated learning were controlled in both conditions. The results were that the amount of RI was greater when both OL and IL were composed of unfamiliar items than when both were composed of familiar ones. Similar findings were obtained in the situation of associative inhibition.

Ishihara (24), in 1951, conducted four experiments on the relations between RI and reminiscence. In his first experiment both control group and experimental group recalled an original list composed of poetry after $1 \mathrm{~min} ., 12 \mathrm{~min} ., 24 \mathrm{hrs}$. and seven days. The amount of RI was greatest in the condition of recall in $12 \mathrm{~min}$. after original learning. As for the reminiscence, the experimental group showed, even in the recall after 7 days, a considerable amount of reminiscence. In his another experiment, the amount of RI was found to decrease after 12 min. up to 5 hrs. He concluded from these results that there must be the third factor of $R I$ which was considered as interference between the traces of OL and IL (ibid. p. 24).

Maeda (61) again conducted in 1951 some experiments on the relation between PI or RI and time interval between OL and RL. Results were that when the time interval between OL and $R L$ was short ( $40 \mathrm{~min}$. or $90 \mathrm{~min}$.), the amount of RI increased as the temporal position of IL approached to RL. But when interval between $\mathrm{OL}$ and RL was long (five hours or two days) and recall was measured by paired associates method, the most favorable point to recall the OL was the middle of the interval between OL and RL.

Experiments on the relation between temporal position of IL and amount of RI were also conducted by Tatsuno (92). Time intervals between OL and RL were $20 \mathrm{~min}$. or $40 \mathrm{~min}$., and materials were nonsense syllables or adjectives. Results were as follows: when the time interval between OL and RL was long, the amount of RI was greatest at the condition in which list was interpolated immediately after OL or before RI, and the amount of RI was smallest when the list was interpolated at the middle of interval. When the time interval is short or the number of items of the original list is small, however, the RI has no relation with the temporal position of IL. He concluded from these results that we must consider the amount of OL, learning grade of OL, and the time interval between OL and RL, as the factors influencing the effect of change of temporal position of IL.

It seems that the interest of Japanese research worker in verbal learning has been shifting again gradually from temporal factor of RI to similarity factors after 1950. Probably it has some relation to the appearence of Osgood's surface in 1949 (80), which schematized the retroaction effect as a function of similarity in $\mathrm{S}$ and $\mathrm{R}$ so clear-cut that it invites readily the experimentation of these hypothesis. The first attack on the Osgood's surface was done by Ishihara 
and Kashu (25) in 1953. In their experiment, the usual PI, RI and control (rest) conditions were set. Recall and relearning trials were held at $5 \mathrm{~min} ., 1 \mathrm{hr}$. and 24 days after original learning. Each list was composed of 6 pairs of consonants on stimulus side and of Japanese verbs on response side. The response words of OL and IL had semantic similarity according to the association list of Kashu and Kubo (39). The result was that there was found a positive transfer from the first list to the second list. The amount of recall in number of items at recall $5 \mathrm{~min}$. after original learning were 5.2 in rest condition, 3.8 in RI condition and 4.3 in PI condition. But after 24 hrs. there were almost no difference between conditions. In their second experiment, the semantic relations between the two response-words of the 1 st and 2 nd lists were either similar, opposite or neutral. Again there was found a positive transfer from the list 1 to list 2 in both similar and opposite conditions. These results do not support the Osgood's hypothesis that when the relation between response items are opposite there occurs a negative transfer. They assert from these results that even between opposite words there are generalization tendencies and these generalizations are accompanied by differentiation at the same time.

The attack upon Osgood's hypothesis was also made by Tatsuno (95). In his experiment the degree of similarity relation between OL and IL was changed in the response side. The response items of OL were nonsense syllables and that of IL were either (a) nonsense syllables which had common element with nonsense syllables in OL, or (b) two-place number or (c) number-letter combination which had only one common element with syllables of $O L$. These methods of controlling similarity in elements are the same method as Robinson's. RI and PI paradigms were designed. The results did not confirm the hypothesis of Osgood, but it seemed rather to support the old Robinson-Skaggs' hypothesis (ibid, p. 36-47). Tatsuno also published a book, which contains an exclusive review on RI, in 1957 (94).

Umemoto also criticized the hypothesis of Osgood in 1956. In his review and critique of similarity problems in verbal learning (105), he supported Morikawa's view that the schemes of transfer and retroaction could not be expressed in a simple figure as in the surface of Osgood, while transfer effect often appeared in more positive (facilitative) direction than retroaction even in the same condition.

In $1954 \mathrm{Kashu}$ and Kubo (39) standardized the association values of three syllable Japanese verbs. In this list they arranged two kinds of association values: one is so-called association. values in the usual sense, in which the number of frequency from listed words are recorded, and they called it as F-association later. The other association values are frequency of appearance as response words in association situation and they called it $\mathrm{T}$-association value (to-association).

Ishihara, Kashu, Morimoto and Kubo (26), in 1957, conducted an experiment on transfer with these standardized verbs as response items. Usual A-B, A-K paradigm of transfer was designed. The semantic relations between two response-words, $B$ and $K$, were either similar, opposite or neutral. But in similar and opposite condition, two more associative relations between $\mathrm{B}$ and $\mathrm{K}$ were set in conditions. In one of these conditions, there was more association value from $\mathrm{B}$ to $\mathrm{K}$ (forward association) than $\mathrm{K}$ to $\mathrm{B}$, and in the other conditions there was more association value from $\mathrm{K}$ to $\mathrm{B}$ (backward association) than $\mathrm{B}$ to $\mathrm{K}$. The findings are that there is more positive transfer when the two response words are in the condition of forward and similar association than others, but in the opposite condition more positive transfer is 
found when two responses are in the relation of backward association. They concluded from the above data that response generalization in such a case could not be explained fully by the “parasitic reinforcement hypothesis' of Underwood (107).

In 1957, Ishihara and Morimoto (27) further tested their hypothesis on the transfer and direction of association. Four groups of subjects learned three lists of 12 pairs, which had nonsense syllables on the stimulus side and Japanese verbs on the response side. In the first learning all four groups learned the same S-A list. In the second learning, groups 1 and 4 learned the list of S-B and the other two groups, group 2 and 3, learned the list of S-b. B and b were different verbs but each had association value in reference to $A$. In the third learning, the list S-C was learned by both groups 1 and 2, and list $S-c$ was learned by the groups 3 and 4 . In these paradigms, there are some semantic relations between A-B-C or A-b-c, but no in A-B-c or A-b-C, though some relations exist between A-C or A-c. According to Ishihara's hypothesis the dimension of generalization must be determined in the second learning. So it is expected that the recall of groups 2 and 4, which learned three lists having no semantic relation between response words will be poorer than the recall of other two groups. This hypothesis was supported by the results; the amount of transfer was greater in the group 2 and 4 than in group 1 and 3.

Shibahara and Oda $(77,87)$ conducted also an experiment on the response relation in retroaction. Typical A-B, A-K, A-B paradigm of retroaction was used. They found that if subjects were asked to respond with any non-B word to stimulus $A$ in interpolated learning, retroactive inhibition did not appear. They concluded from the results that unlearning of OL would be inhibited when subjects took a set which inhibits the original response.

We can see that these experiments which have been reviewed above are all dealing with the problem of response interaction in transfer or retroaction situations. Although the tendency is not seen only in Japanese studies, the focus of research in verbal learning, for the time, will be found in the response factor, especially the semantic relations between two or more response words.

\section{SPREAD OF EFFECT}

There are more than fifteen articles in Japan on the spread of effect and most of these experiments have been done by Koyanagi and Iwahara. In 1953 Koyanagi (49) found for the first time that a type of spatial sequence habit exists in the human repertory as well as the number sequence habit. In his first experiment, subjects were asked to mark on any one of 9 nonsense figures on each page one after another. As a result, it was found that subjects marked on the figures near to those on which he marked on the previous page. In his second experiment subjects were instructed to write down any number from one to nine in random order. When a number was designated in a certain column of paper, there was found the gradient of number repetition before and after the designated number. From these results he concluded that the guessing-sequence habit was the cause of the spread of effect and there was some other guessing habit such as the spatial one.

In his second paper, Koyanagi (50) reported two experiments. The purpose of the first experiment was to see the effect of set and inter-trial time intervals upon gradient of repetition. In the condition A, subjects were instructed to make number response to each nonsense sylla- 
ble at the rate of one second between trials. In the condition $\mathrm{B}$, the time interval between trials was $6 \mathrm{sec}$. In the condition $\mathrm{C}$, subjects were instructed to give attention to the previous and following response of the rewarded one. The results showed that only in the condition A the gradient of repetition appeared. In his second experiment the gradient of repetition around punished response was analyzed. Typical concave gradient of punishment was obtained in repetition of number responses to a nonsense syllable list, both in punishment situation and ronpunishment situation, in which subjects were instructed only not to repeat the response to a designated syllable.

The purpose of the third experiment of Koyanagi (51) was to examine the three conflicting hypotheses of Thorndike (97), Zirkle (115), and Jenkins-Sheffield (38) on the spread of effect. As material he used nonsense syllables on the stimulus side and nine nonsense figures on the response side. There were four conditions. For all conditions except $\mathrm{B}$, two stimulus syllables out of 18 nonsense syllables were isolated by changing the color of letters in the syllables. Usual reward and punishment by saying 'right' or 'wrong' were given to subjects in conditions A and B. The arrangements of response materials (nonsense figures) were changed. except in condition C. As the results, the gradient of repetition or "spread of effect" was found only in the condition $\mathrm{C}$, in which the arrangement of response materials was fixed. This result favors only the guessing sequence hypothesis of Jenkins-Sheffield (38).

The first experiment of Iwahara (29) appeared in 1955. His hypothesis was that when meaningful words and nonsense syllables were presented to subjects as stimulus lists, the gradient of number repetition would be greater for nonsense syllables than meaningful words, because that meaningful stimulus would be more readily connected with response items (number) and these S-R connections would interfere with the R-R connections of guessing sequence habit. The results were that although the amount of correctly recalled responses were greater for meaningful condition, the gradient of number repetitions was greater for nonsense condition, as he predicted. These results also supported the guessing sequence hypothesis.

The experiment in his second paper (30) is very similar to that of Jenkins and Cunningham (37). A typical work-number situation was used with prearranged reinforcement of responses. The position of rewarded words was shifted on alternative trials, while that of unrewarded ones was kept constant. If Thorndike's theory is valid, the gradient of effects should appear around the rewarded words, on the other hand the lack of the gradient was expected by the guessing sequence interpretation. His result favored also the guessing sequence hypothesis of the "spread of effect."

In his third paper (31), he intended to explain the following two facts in the terms of the guessing sequence hypothesis: (a) the fore-gradient of the spread of effect and its relative weakness compared with the after-gradient ; (b) the higher level of repetition in the Thorndikean learning situation than in the non-learning situation. In the first experiment subjects wrote numbers from one to ten at the rate of $3 \mathrm{sec}$. per inter-trials. Two series of 240 such responses were obtained. When the number of repetitions in the three positions around chance repeats on 6 th, 13 th and 20 th rows were computed, a clear fore-gradient as well as an ordinary aftergradient was obtained. He asserted that it could be explained only by the number-guessing habits. In the second experiment, two numbers in every column were presented by the ex- 
perimenter after an extra $3 \mathrm{sec}$. pause in order to avoid any voluntary number responses after subjects were given numbers. Result was that only an after-gradient was obtained around pairs of the same numbers specified by $\mathrm{E}$. The lack of a fore-gradient was, he said, assumed to be due to interruption of S's guessing sequences by being given specified numbers by E. In another experiment, two responses in every column were called 'important' and no numbers were specified by $\mathbf{E}$. A weak gradient preceding chance repetition of responses which were called 'important' was shown. These results were interpreted as showing that S's guessing sequence was not discontinued. As a conclusion from these results, he said that the fore-gradient could be explained also by the guessing-sequence hypothesis.

In his fourth paper (32), he examined both individual number guessing tendencies as well as group number-guessing habits, as functions of inter-response intervals. The following results were obtained : the gradients of response repetition around chance repeats between trials were slightly sharper for the $3 \mathrm{sec}$. group than for the $6 \mathrm{sec}$. group in reference to interresponse interval. He interpreted this data as showing that when inter-trial time was too long, the cue character of the previous trial was lost and individual number preference appeared.

His fifth paper (33) was concerned with the spread of effect in a punishment situation. He found that the after-gradient appeared only when the cue stimulus was nonsense syllable, and there were not any fore- and after-gradient in a condition using meaningful words. With regard to spread of effect in a punishment situation, he agreed with the regression theory of Stone (118) and attempted to explain with the more general theory of distraction by isolation.

In his sixth paper (34), Iwahara attempted to test the Thorndikean hypothesis in paired associates learning, with the collaborator Soeda. But they could not find any gradient of repetition in a paired associates situation. In the seventh paper (35), Iwahara found with collaborators that the number guessing habit of children was almost as same as that of adults.

Although the mechanism of 'spread of effect' is now almost thoroughly explored and the guessing sequence hypothesis is supported by almost all psychologists, there remain even yet a considerable number of problems unsolved such as the effect of punishment, individual and developmental differences in the number guessing habit, the relation with serial position effect and so on. Murata (74) has done an excellent review upon the problem of verbal punishment in 1957. Some studies on the number guessing habit and number preference bahavior were already done by Uchida (99) in 1935 and Obonai (76) in 1938 and 1955. It is to be hoped that Japanese psychologists will make a considerable contribution in the future also to the research in this field.

\section{INCIDENTAL LEARNING}

The first study in Japan of incidental learning was done by Takagi and Takehara (91) in 1930. In their first experiment, a stimulus list was composed of eleven nonsense syllables which were printed with black or red ink. Subjects in three groups tried to learn the list under three different instructions, that is (a) to memorized only the black syllables, or (b) red syllables or (c) all syllables both black and red. Results were that the amount of recall of relevant stimulus (either red or black) which Ss had been instructed to learn by the the experimenter, was 4.0 words whereas that of irrelevant stimulus were only 0.5 words. In the second experiment, 
also, nine syllables were presented in nine slits in a panel board successively. Subjects were instructed (a) to memorized the nonsense syllables in successive order, or (b) to memorize the syllables with reference to its spatial localization. These sets were changed or maintained when recall were made. When a set was changed in the recall trial, the amount of recall was 4.0 on the average whereas 6.0 words were recalled under the same conditions as in the original learning.

The second study in Japan on incidental learning was done by Tsuji (98) in 1935 . The experimental task was to divide a paper form-board by a scissors into two pieces such that they could compose a square. After the problems were solved, subjects were asked to recall the original forms of the paper boards. Tsuji found that the recall of original stimulus was not upon the cue of memory trace but its was done by the progressive retrospection of problem solving process.

Recently Koyanagi made a series of experiments on incidental learning. In his first paper (52), the hypohesis of Postman and Phillips (81), which asserts that the isolation of Siegel type is to be seen only in intentional learning, was tested. Isolation was made by controling the material of lists, composed of nonsense syllables, meaningful words, numbers and colors. Results supported the findings of Postman and Phillips.

In his second experiment (53), the isolation effect of Restorff type was found both in intentional and incidental conditions. But there was no effect of perceptual isolation such as might be seen when a colored item was inserted into non-colored items in a list.

In his third paper (54), two experiment were reported. In the first experiment two lists of 16 nonsense syllables, in which the intra-list formal similarity was controlled, were learned by subjects, both in intentional and incidental conditions. The results showed the effect of intra-list similarity was significant only in the incidental learning condition. In the second experiment one group of subjects learned two lists of nonsense syllables of high and low association value, and the other group of subjects was forced to do association tasks on the same two lists. Results were that, the higher the association values of list, the better the rate of recall in both incidental and intentional learning conditions. Furthermore the amount of recall was greater for the free association group than for the forced association group in the intentional learning condition, while it was greater for the forced association group than for the free association group in the incidental learning condition. He concluded from the above results that incidental learning with verbal materials was the function of differential responses (Postman) (119) such as association responses, the clustering responses and so on.

In the experiment of Koyanagi's fourth paper (55), two lists composed of ten items of a three letter anagram were used as the stimulus materials. The anagrams of list A were easy to solve (reversed order) while those of list B were more difficult. Subjects of the control group were instructed only to copy the original stimulus. Results showed that both the amount of recall of the original items and correct answers in list $A$ were greater in the experimental group than in the control group. But the amount of recall of the original items in the list $\mathrm{B}$ was not greater in the experimental group than the control group though the recall of correct responses was greater. From these results, he concluded that the anagram activity as the means of producing differentiating responses was effective in incidental learning so far as its processes were 
apt to recur.

In his fifth paper, Koyanagi (56) reported an experiment on the effect of sentence making task upon later recall of stimulus materials. Stimulus list was composed of meaningful words in 14 pairs. In the incidental condition, subjects were divided into two groups. One group of subjects engaged in sentence making with the original materials, and the other engaged in choice of the column in which subjects were to write down the stimulus words. In the intentional condition, subjects in two groups were also engaged in those two orienting tasks but they were instructed to memorized the stimulus materials at the same time. As the results only interaction between instruction and task was significant. Although the amount of recall of stimulus materials in pairs was greater for the intentional group than the incidental one, the difference between the two groups was greater for the column choice groups than for the sentence making groups.

In his sixth paper (57), the effects of rate and number of stimulus presentation were studied. The stimulus list consisted of 12 nonsense syllables. The orienting task was to write down the stimulus words in any of the four blanks on a given card. As the result, it was found that the differences between the amount of recall between intentional and incidental learners depend. on the rate and number of stimulus presentations : when the list was presented only once at the rate of one item every 4 sec., no difference between intentional and incidental conditions. was found. In the case of slow rate (presented once at the rate of one item every $12 \mathrm{sec}$.) or many presentations (thrice at the rate of every $10 \mathrm{sec}$.), however, the scores of intentional learners were significantly higher than those of incidental learners. He interpreted the improvement showed in the scores of intentional learners when the time or number of presentations increased, as the effect of increasing rehearsal of subjects on the original stimulus.

Morikawa (70) made a exclusive review on the studies of incidental learning. He pointed out that there was some confusion between the concepts of latent learning and incidental learning, and he proposed tentative resolution to this problem.

\section{Functions of Stimulus and Response Words}

All of these studies that were reviewed above in this paper have treated problems on which American and European psychologists also have done many experiments. But there is a problem to which few American and European psychologists have given attention. It is the problem of the functions of stimulus and response words. As the beginning experiments on. this problem we can find the experiments of Kuraishi (58) in 1937. The phenomenon which he treated in his paper was the relative difficulty in recall of a foreign laguage from the mother language compared with the recall in the reverse order. We may call it the Kuraishi-phenomenon, in memory of the discoverer of the phenomenon. In his first experiment, subjects were asked to translate 50 German words into Japanese or Japanese words into German. As the results showed both in the reaction time and number of errors and no answer, it was easier for Japanese subjects to translate the foreign words (German) into Japanese than Japanese into foreign words. Furthermore he found a similar effect of unbalance in the recall of pairs of such materials, as meaningful word and nonsense syllables, family names and nonsense syllable, meaningful words and capital letters in alphabet (letter is easier to recall), family name and two. 
place numbers and so on. Kuraishi's findings can be summarized in this proposition; that it is easier to recall the pair which has such items on the response side that will be more recalled in a free recall situation, than to recall the pair which has the same items in stimulus side (ibid. p. 587). In his eighth experiment, Kuraishi used the nouns of Ainu language which were unfamiliar to Japanese as the stimulus materials. In the prior learning, one list composed of nouns of Ainu was paird with their Japanese equivalents and the other list was paired with threeplace numbers, which were more difficult to learn than Japanese meaningful words. After each list was completely retained, the two lists of Ainu, each of which was either paired with Japanese equivalents or three place numbers, were set into pairs again and recall test of the paired associated type were made. The finding was that it is easier to recall the items of Ainu which were previously paired with the Japanese equivalent than the other items of Ainu which were paired with three place number. He interpreted these results as showing that the Ainu paired with its Japanese equivalent became meaningful while the other Ainu which had been paired with three place numbers remained nonsense for Japanese subjects. His final conclusion was that "In short, in the thought-configuration in which one of its articulated members has the systematized background and the other has not, the reproduction in accordance with the method of paired associates, namely 'Lück-Ergänzung,' is more favorably achieved when the latter comes first into consciousness." (58, English abstract p. 56)

From these studies of Kuraishi it is confirmed that the recall of the "systematized member" from "unsystematized member" is easier than to recall in the reverse order. But what is the meaning of the "systematized" member or items? Kuraishi defined the systematized items operationaly as those which were more retained in free recall situation. But Sagara (84) in 1939 found that in some cases it was more difficult to recall the systematized member from unsystematized one. "Systematized items" in Sagara's meaning was that of a series of letters (Japanese or English) which were arranged so as to make a sentence or meaningful words. In such a case, it was easier to recall from systematized letter the unsystematized one than in reverse direction. Sagara compared this effect with the figures of Gottschaldt (16) in which part figures were too tightly fixated in the systematized whole so that subject could not recognized the part figure easily.

After a period of about ten years, Umemoto (102) again tried to analized the cause of unbalance in paired associates learning. He stated that there were two factors which cause the unbalance of recall in paired association. One is the order of S-R items in original learning, the other is the meaningfulness or familiarity of items in the paired associates list. In one of his experiments, subjects learned 8 pairs of nonsense syllables by the anticipation method. Recall tests were made after 7 trials in forward direction (stimulus to response) or backward direction (response to stimulus). Results were that the amount of recalled items was greater in the condition in which the direction of S-R in original learning and recall test coincided than in the condition of not coinciding. But when lists were made, in his second experiment, from pairs of alphabet letters (easy to learn) and nonsense syllables (difficult to learn), more items were recalled from nonsense syllables to alphabet letters than in reversed order, even in the case of no coincidence between the direction of original learning and recall trial. These results are to be regarded as confirming the findings of Kuraishi that it is easier to recall easy 
items from difficult ones than in reverse order. But to compare the forward recall and backward recall directly, as Kuraishi did, implies changes in two variables of stimulus and response, at one time. If we want to compare the relative function of stimulus and response words eparately, it is necessary to make four lists, in the two lists of which only stimulus condition are varied such as $\mathrm{A}-\mathrm{K}, \mathrm{B}-\mathrm{K}$, and in the two other lists in which response conditions are varied such as $\mathrm{K}-\mathrm{A}, \mathrm{K}-\mathrm{B}$. Thus Umemoto conducted an experiment in which four lists were learned by each subject by anticipation method. List $\mathrm{A}$ and $\mathrm{B}$ had the same kind of response words (meaningful words) and different stimulus words (alphabet and nonsense syllables), and list C and $\mathrm{D}$ had a same kind of stimulus words and different kind of response words. The results showed that the mean number of trials to one perfect learning were, list $\mathrm{A} ; 5.0$, list $\mathrm{B} ; 7.9$, list C; 3.3 and list D; 14.6 respectively. From these results he concluded that paired associates learning was determined more largely by the response factor than the stimulus factor. His final conclusion was that stimulus words serve as a sign for response words in paired associate learning, and what is demanded of the subject is only to discriminate between them, whereas response words must be fully performed, announced or written down, and it will need more expenditure of energy.

The findings of Umemoto were supported by the experiment of Morikawa in 1955 (68). In this paper he showed that the difference between forward recall and backward recall, which he named as "forward-backward recall gradient," was a new and useful index in verbal learning. Many experiments were done on the relation between this "forward-backward recall gradient" and material, overlearning, method, criteria of learning, interpolated recall and learners familiarity with the list. The details of his works will be stated by him in the another article in this issue. Recently he found (67) new data on this problem. He made an experiment in which the intra-list formal and semantic similarity were controlled both in stimulus and response side. Materials were nonsense syllables and adjectives, the similarity of which were rated and standardized by Umemoto, Morikawa and Ibuki (103). The result was that paired associate learning was more influenced by the intra-list similarity of stimulus items than that of response items. It may appear that the results contradict the findings of Umemoto, but when the function of stimulus and response words in paired associate learning are considered, the results do not contradict the hypothesis. Since the demanded task in stimulus words in paired associates lists is discrimination learning, and in response words is acquisition learning, it can be understood naturally that similarity, which is the essential variable of discrimination learning, has more effect upon stimulus items than response ones.

In his second paper (69), Morikawa showed that the meaningfulness which was related to the difficulty of acquisition of verbal material was the main variable of response words. So when retention was measured by the recognition method, which demanded of subjects only a discriminating behavior, the difference between the amount of recall of stimulus words and response words disappeared.

From the above review we can see that the main variables of paired associate learning are (a) the direction of the pair in both original and recall trial, (b) the similarity of stimulus words and (c) the familiarity of response words. Are these all the factors which determine the rate of recall in paired associate learning? Umemoto (105) showed further that there was another 
factor of similarity between stimulus and response in paired associate learning. Such a similarity might be called inter-stimulus-response similarity, and is already treated in the experiments of Köhler (47) and Mandler (62). Umemoto reported in his paper three experiments on the inter-stimulus-response similarity. Each stimulus list was composed of 8 pairs, in which meaningful Kanji (Chinese style letter) were in the stimulus words, and Kana (Japanese style letter) were in the response side. The response letters were identical with stimulus Kanji or similar to stimulus Kanji. In the identical condition, the response letters were only pronunciations of stimulus Kanji. The following generalizations were made from his experimental results : (1) When there are identical items both in the stimulus side and the response side in a

$\begin{array}{lccc}\text { B }-\mathrm{E} & \mathrm{B}-\mathrm{Q} & \mathrm{B}-\mathrm{E} & \mathrm{B}-\mathrm{Q} \\ \mathrm{F}-\mathrm{K} & \mathrm{F}-\mathrm{L} & \mathrm{F}-\mathrm{K} & \mathrm{F}-\mathrm{K} \\ \mathrm{S}-\mathrm{J} & \mathrm{S}-\mathrm{A} & \mathrm{S}-\mathrm{J} & \mathrm{S}-\mathrm{A} \\ \mathrm{K}-\mathrm{F} & \mathrm{K}-\mathrm{T} & \mathrm{K}-\mathrm{F} & \mathrm{K}-\mathrm{F} \\ \mathrm{R}-\mathrm{M} & \mathrm{R}-\mathrm{C} & \mathrm{R}-\mathrm{M} & \mathrm{R}-\mathrm{C} \\ \mathrm{M}-\mathrm{R} & \mathrm{M}-\mathrm{P} & \mathrm{M}-\mathrm{R} & \mathrm{M}-\mathrm{R} \\ \mathrm{J}-\mathrm{S} & \mathrm{J}-\mathrm{X} & \mathrm{J}-\mathrm{S} & \mathrm{J}-\mathrm{X} \\ \mathrm{E}-\mathrm{B} & \mathrm{E}-\mathrm{N} & \mathrm{E}-\mathrm{B} & \mathrm{E}-\mathrm{B} \\ \text { common } & \text { no common } & \text { common } & \text { half of } \\ \text { items } & \text { items } & \text { items } & \text { items } \\ \text { in SR } & \text { in SR } & \text { in SR } & \text { common } \\ & & & \text { in SR }\end{array}$

Fig. 1

Scheme of inter-S-R similarity (1)
Fig. 2

Scheme of inter-S-R similarity (2)

$\begin{array}{cc}\text { B }-\mathrm{q} & \mathrm{B}-2 \\ \mathrm{~F}-1 & \mathrm{~F}-8 \\ \mathrm{~S}-\mathrm{a} & \mathrm{S}-6 \\ \mathrm{~K}-\mathrm{t} & \mathrm{K}-5 \\ \mathrm{R}-\mathrm{c} & \mathrm{R}-3 \\ \mathrm{M}-\mathrm{P} & \mathrm{M}-9 \\ \mathrm{~J}-\mathrm{X} & \mathrm{J}-4 \\ \mathrm{E}-\mathrm{n} & \mathrm{E}-7 \\ \text { no common } & \text { no common } \\ \text { items but } & \text { items and no } \\ \text { similarity } & \text { similarity } \\ \text { between } & \text { between } \\ \text { SR groups } & \text { SR groups }\end{array}$

Fig. 3

Scheme of inter-S-R similarity (3)

paired associate list, and the position of stimulus and response in a list are not in correspondence, (as in Fig. 1) the rate of learning and amount of recall are more unfavorable than in the case where exist no identical items between stimulus and response. (2) The amount of recall was. smaller when half of the stimulus and response items are common (Fig. 2) than when all the items are common. (3) When there are no common items between stimulus words and response words and there is also intra-stimulus-group similarity and intra-response-group similarity (Fig. 3), the rate of learning become lower the more similar the stimulus word group and the response word groups are. (4) When there are no identical items between stimulus words and response words and also no intra-list similarity in stimulus and response words, the more similar the stimulus and response words are to each other, the more items are recalled.

\section{Retrospect AND Prospect}

I have sketchily reviewed the main streams of Japanese studies in verbal learning. There are still more studies to which I have been unable to refer here. Developmental studies of memory and verbal learning have been made by Masuda, Takahashi and Ingu (63, 1928), Aoki $(8,9,1931)$, Sato $(85,1933)$, Onishi $(78,1938)$, Mishima and Yokoo $(66,1957)$ and many others. Chiba and Susukida (12) made a study on a memory prodigy (1934). Also studies on the effect of shock and amnesia were made by Kiyohara and Aiba (45, 1952), Arai and Obonai (10, 1954). Sugiyama and Goto found some relations between anxiety and rote learning (90). Kitano conducted a series of experiments on the effect of subjects' attitudes toward stimulus items. $(42,43$, 
44), Studies on memory for finished and unfinished tasks were done by Yokoyama (113), Azuma (11), Ito (28), and others.

It might seem that there are no cultural differences between Japanese studies and American or European studies on verbal learning. Because the materials on verbal learning are in the language of each country, however, it follows that the characteristics of each language determine the direction of the study of verbal learning in each country. Now what are the characteristics of the Japanese language: It is certain that Japanese has a more complex and unique character than any other foreign language. For instance Japanese has more than three styles of letters, that is, Kanji (Chinese style), Kana, Hirakana and Roman type. So we can manipulate more dimensions of formal similarity and familiarity than foreign researchers.

Although we have not such a standardized list of frequency of usage as Thorndike and Lorge's, we already have many standardized lists of nonsense syllables, verbs, and adjectives for experiments in verbal learning. Moreover, these lists have a unique characteristic which American lists do not have. The first standardization in Japan of association values of nonsense syllables was done by Umemoto (101) in 1950. In the second standardization of the table by Umemoto, Morikawa and Ibuki (104), all possible combinations of Japanese two-letter pure sounds were measured for association values and maeningfulness in terms of Noble (116). It follows that this table contains both nonsense syllables and meaningful words of two letters in a single continuum of association value and meaningfulness. According to this table, we can manipulate both nonsense syllables and meaninfgul words in a single scale.

More uniqueness is seen in the list of verbs standardized by Kashu and Kubo (39). In this table, association values, in the sense of frequency of appearance as response words to stimuli, were listed. There can also be found similar and opposite words to stimulus words in this table of response words in association. I have already referred on previous pages to the new index of T- and F- association values which Ishihara, Kashu and others (26) have deduced from the table. Morimoto, Kashu and Nakata (72) applied the method of semantic differentials of Osgood (117) to the ten verbs of this list and made a factor analysis of the scores of association values, and of the difference between rated scores (D-score). Clearly differentiated features of factor scores were obtained by similar and opposite words. Thus reliability of this table will be proved more and more in the future.

The other standardized list is that of adjectives by Umemoto, Morikawa and Ibuki. (103) The content of this table is similar to that of Haagen (17). But in this table many response words are recorded with their association values, similarity, and familiarity rated by university students. For example, as the response word to "high" the following scores of similarity were measured for each word; precious-7.0, noble-6.0, excellent-4.0, long-2.0, great-1.7. Fifteen to twenty words are listed as responses to each of 120 adjectives. From this table we can compose many lists having various degree of inter- and intra-similarity, and with these lists we can make experiments on the relation between inter- and intra-similarity and transfer, retroaction, massed and distribution effect, as seen in the experiments of Morikawa (67), Shimizu (88), Haraguchi (20), Kazusa (41) and Nemoto (75). Of course study in verbal learning is not determined solely by these material, however, there is no doubt that the characteristics of these material as tolosfor laboratory research will be among the deciding factors for 
future work in Japan.

\section{REFERENCE}

1. * Abe, K. An investigation of the law of memory trace deviation (1) : Reproduction method and its verification. Jap. J. Psychol., 1951, 21, No. 1, 33-46.

2. * Abe, K. An investigation of the law of memory trace deviation (2) : Single recognition method. Jap. J. Psychol., 1951, 21, No. 2, 29-37.

3. Akishige, Y. Studies on constancy problem in Japan. Psychologia, 1958, 1, 143-157.

4. $\star \star$ Amano, T. Perception of visual forms and its reproduction (1). Jap. J. Psychol., 1930, 5, 657-674.

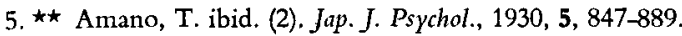

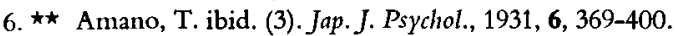

7. $\star \star$ Amano, T. Change of memory trace-On the methodology of its study-Jap. J. Psychol., 1933, 8, 843-855.

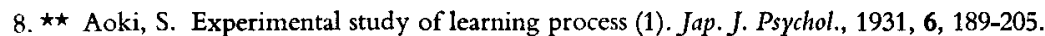

9. $\star \star$ Aoki, S. Experimental study of learning process (2). Jap. J. Psychol., 1934, 9, 195-216.

10. $\star$ Arai, K. \& Obonai, T. A hypothesis of memory stratum (4) - A study by electro-convulsive shock-. Jap. J. Psychol., 1954, 25, 155-164.

11. * Azuma, Y, Some conditions determining the resumption of an interrupted task. Jap. J. educ. Psychol., 1954, 2, 162-168.

12. $\star \star$ Chiba, T. \& Susukida, T. A study on abnormal memory. Jap. J. Psychol., 1934, 9, 749-770.

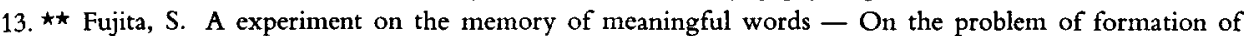
region. Jap. J. Psychol., 1938, 13, 77-86.

14. Gibson, J. J. The reproduction of visually perceived forms. J. exp. Psychol., 1929, 12, 1-39.

15. Goldmeier, E. Progressive changes in memory traces. Amer. J. Psychol., 1941, 54, 490-503.

16. Gottschaldt, K. Über den Einfluss der Erfahrung auf die Wahrnehmung von Figuren. I. Über den Einfluss gefaufter Einprägung von Figuren auf ihre Sichtbarkeit in umfassenden Konfigurationen. Ps ychol. Forsch., 1926, 8, 261-317.

17. Haagen, C. H. Synonymity, vividness, familiarity, and association value ratings of 400 pairs of common adjectives. J. Psychol., 1949, 27, 453-463.

18. Hanawalt, N. G. \& Post, B. E. Memory trace for color. J. exp. Psychol., 1942, 30, $216-227$.

19. Hanawalt, N. G. The method of comparison applied to the problem of memory change. J. exp. Psychol., $1952,43,37-42$.

20. $\star \star$ Haraguchi, M. A study in paired associates learning. Unpublished B.A. thesis, Kyoto Univ., 1957.

21. Hebb, D. O. \& Foord, E. N. Errors of visual recognition and the nature of the trace. J. exp. Psychol., $1945,35,335-348$.

22. Irwin, F. W. \& Seidenfeld, M. A. The application of the method of comparison to the problem of memory changes. J. exp. Psychol., 1937, 21, 363-381.

23. Irwin, F. W. \& Rovner, H. Further study of the method of comparison applied to the problem of memory changes. J. exp. Psychol., 1937, 21, 533-544.

24. * Ishihara, I. The process of retroactive inhibition in retention. Jap. J. Psychol., 1951, 21, No.3, 4, 18-25.

25. * Ishihara, I. \& Kashu, H. The learning of response-words in similar, opposite or neutral relations. -A study on the conditioning principle in verbal learning. Jap. J. Psychol., 1953, 24, 1-12.

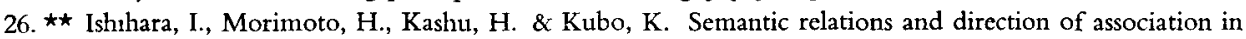
verbal learning. Stud. Human., 1956, 7,

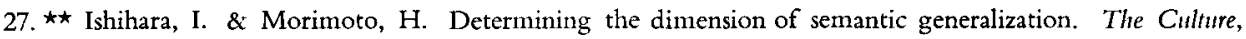
1957, 21, 2.

28. * Ito, M. The relationship between success-failure and completed-incompleted task. - The effects of the recall. Jap. J. Psychol., 1957, 27, 249-269.

29. * Iwahara, S. Studies on 'spread of effect': I. On the quality of stimulus words. Jap. J. Psychol., 1955, 26, 231-234.

30. Iwahara, S. Studies of the 'spread of effect' : II. The shift of the position of rewarded words. Jap. 
psychol. Res., 1956, No.3, 1-7.

31. Iwahara, S. ibid. III. The fore-gradient and number guessing habits. Jap. J. Psychol., 1956, 27, $227-234$.

32. * Iwahara, S. ibid. IV. Analysis of serial responses in number guessing based on group and individual data. Ann. Rep. Stud. hum. soc. Science, 1958, 1, 127-143.

33. Iwahara, S. ibid. V. The spread of the effect of verbal punishment and the meaningfulness of cuestimuli. Jap. psychol. Res., 1958, No.5, 38-50.

34. * Iwahara, S. \& Soeda, N. VI. Spread of effect in paired associates learning. Jap. J. Psychol., 1958, 28, 320327.

35. * Iwahara, S. ibid. VII. Theoretical study. Jap. psychol. Rev., 1958, 2, 1-13.

36. * Iwahara, S., Hirata, M. \& Nukina, Y. ibid. VIII. The spread phenomenon and number guessing habits in children. Tohoku J. exp. Psychol., 1958, 2, 25-29.

37. Jenkins, W. O. \& Cunningham, L. M. The guessing-sequence hypothesis, the "spread of effect," and number guessing habits. J. exp. Psychol., 1949, 39, 158-168.

38. Jenkins, W. O. and Sheffield, F. D. Rehearsal and guessing habits as sources of "spread of effect." J. exp. Psycholo, 1946, 36, 316-330.

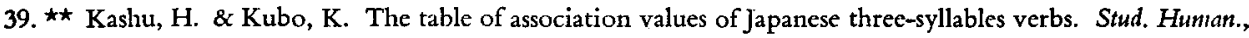
1955, 5, 73-105.

40. * Katsui, A. \& Obonai, T. Characteristics of errors in the recognition and reproduction of geometrical figure. Jap. J, Psychol., 1957, 27, 352-361.

41. ** Kazusa, K. Problems of distributed practice in serial verbal learning - As a function of intra-list similarity. unpublished B.A. thesis, Kyoto Univ., 1958.

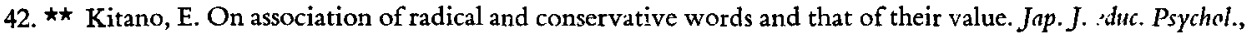
1954, 2, 109-112.

43. * Kitano, E., On the influences of radical and conservative words and their values upon the visual recall and recognition. Jap. J. Psychol, 1955, 25, 225-229.

44. * Kitano, E. On the influence of materials upon learning process. Jap. J. Psychol., 1957, 28, 168-172.

45. * Kiyohara, K. \& Aiba, H. On a case of retrograde amnesia - The results of psychological test. Jap.J. Psychol., 1952, 23, 80-87.

46. Köhler, W. \& Restorff, H. Analyse von Vorgängen im Spurenfeld. Psychol. Forsch., 1935, 21, 56-112.

47. Köhler, W. On the nature of association. Symposium on recent advances in psychol., 1941.

48. $\star \star$ Komatsu, H. A study on the reproduction of perceived forms by children. Jap. J. Psychol, 1931, 6, 569-590.

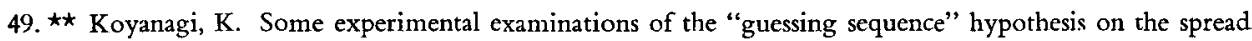
of effect. Tohoku J. exp. Psychol., 1953, 1, 20-26.

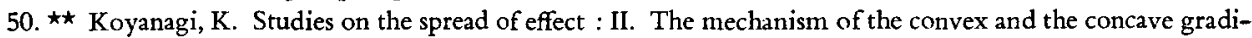
ents of the response-repetition. Tohoku I. exp. Psychol., 1954, 1, 45-50.

51. * Koyanagi, K. ibid. III. An experiemental examination of the three conflicting hypothesis. Jap. J. Psychol., 1956, 26, 295-303.

52. * Koyanagi, K. Studies in incidental learning : I. Intention of learning and isolation effect. Jap. J. Psychol., $1957,27,270-278$.

53. Koyanagi, K. ibid. II. Intra-serial interference. Tohoku Psychol. Folia, 1957, 15, 3-4, 1-11.

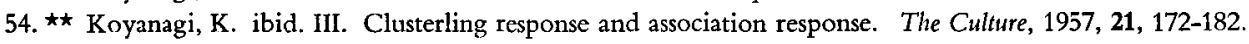

55. * Koyanaki, K. ibid. IV. The role of modifying response. J. Hokkaido Gakugei Unir., 1958, 8, 129-135.

$56 \star \star$. Koyanagi, K. ibid. V. The effect of instruction to learn and composition task on recall of paired-stimulus items. Tohoku J. exp. Psychol., 1958, 2, 43-48.

57. * Koyanagi, K. Ibid. VI. The effect of rate and number of stimulus-presentation. Jap. J. educ. Psychol., $1958,6,36-41$.

58. * Kuraishi, S. On the reproduction of the simple thought-configuration by using the method of paired associates. Jap. J. Psychol., 1937, 12, 578-602.

59. * Maeda, K. On the reproductive inhibition. I. Jap. J. Psychol., 1940, 15, 181-206.

60. * Maeda, K. ibid. II. Jap. J. Psychol., 1940, 15, 261-281.

61. * Maeda, K. An experimental study on factors of reproductive inhibition. I. Inhibitory effects on the reproduction. Jap. J. Psychol., 1951, 21, No.3, 4. 1-17. 
62. Mandler, G. Response factors in human learning. Psychol. Rev., 1953, 61, 235-244.

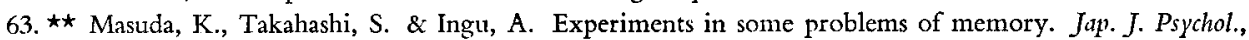
1928, 3, 364-402.

64. * Matsumoto, K. \& Motokawa, K. On the dependence of retroactive inhibition on types of learning. Jap. J. educ. Psychol., 1957, 5, 18-24.

65. Melton, A. W. \& Von Lackum, W. J. Retroactive and proactive inhibition in retention : evidence for a two-factor theory of retroactive inhibition. Amer. J. Psychol., 1941, 157-173.

66. * Mishima, J. \& Yokoo, T. A study on the process of visual and auditory memories. Jap. J. educ. Psychol., $1957,5,1-8$.

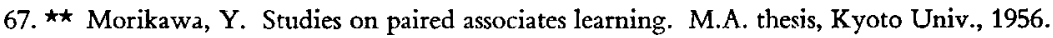

68. * Morikawa, Y. Studies in paired associates learning. (1) Forward-backward recall gradient. Jap. J. Psychol., 1955, 26, 156-171.

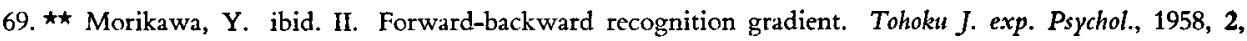
57-62.

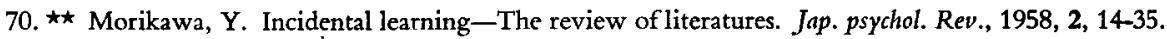

71. * Morikawa, Y. Studies in paired associates learning. III. The influence of meaningfulness and familiarity of stimulus and response words upon learning and recall. Jap. J. Psychol., 1959. (in press)

72. * Morimoto, H., Kashu, H. \& Nakata, Y. A study of semantic relation by the association method and the semantic differential method-Analysis of synonym and antonym. Jap. J. educ. Psychol., 1957, 4, 131-137.

73. Müller, I. Zur Analyse der Retentionsstörung durch Häufung. Psychol. Forsch., 1938, 32.

74. * Murata, K. The effect of verbal punishment in multiple choice learning. Human Stud., 1957, 8, No.3.

75. $\star \star$ Nemoto, N. On the influence of systems of learning material upon verbal learning. B.A. thesis. Kyoto Univ., 1957.

76. * Obonai, T. Factors influencing the recall of compound numbers-Contributions to the study of psychophysiological induction (44). .Jap. J. Psychol., 1955, 26, 1-11.

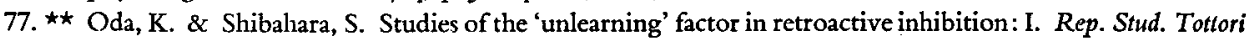
Univ. Dept. Gakugei, 1950, 6.

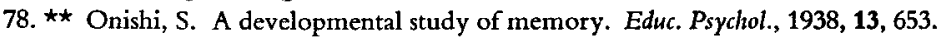

79. Ono, S. A mathematical analysis of serial verbal learning. Jap. psychol. Res., 1958, No.6, 1-21.

80. Osgood, C. E. The similarity paradox in human learning: a resolution. Psychol. Rev., 1949, 56, $132-143$.

81. Postman, L \& Phillips, L. W. Studies in incidental learning: I. The effects of crowding and isolation. J. exp. Psychol., 1954, 48, 48-56.

82. * Sagara, M. Homogeneity and heterogeneity of process and trace by the reproduction. Jap. J. Psychol., 1936, 11, 123-144.

83. * Sagara, M. The mechanism of assimilation as inhibiting factor in memory. Jap. J. Psychol., 1939, 14, 9-28.

84. * Sagara, M. Recall of items in paired associates. Jap. J. Psychol., 1939, 14, 89-96.

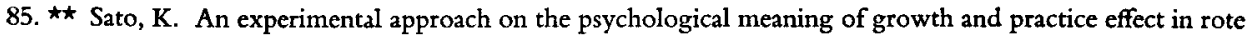
learning. Jap. J. Psychol., 1933, 8, 857-890.

86. Seidenfeld, M. A. Time as a factor in the recognition of visually perceived figures. Amer. J. Psychol., $1938,51,64-82$.

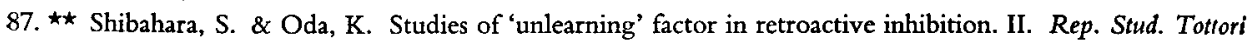
Univ. Dept. Gakugei, 1950, 6.

88. * Shimizu, Y. Transfer as a function of intra- and inter-list generalization. B.A. thesis. Kyoto Univ. 1956.

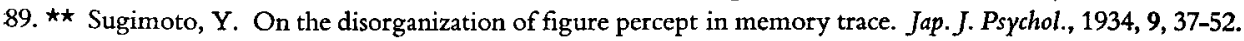

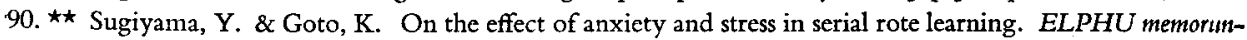
dum report. No.3, 1955. (Hokkaido Univ.)

91. * Takagi, K. \& Takehara, T. Some experimental studies on the process of memory. Jap. J. Psychol., 1930, 5, 629-635.

92. * Takemasa, T. \& Hashimoto, J. An experimental study on the theory of retroactive and proactive inhibition, and some findings about the process of facilitation. Jap. J. Psychol, 1938, 13, 378-388.

93. Tatsuno, Ch. \& Obonai, T. Facilitation and inhibition in memorizing a series of digits or letters. Jap. J. psychol. Res., 1954, No.1, 1-8.

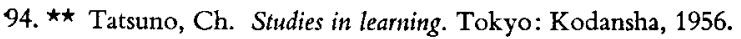




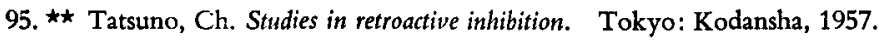

96. Tennies, L. G. Memory traces and perception in the blind. J. exp. Psychol., 1942, 30, 23-39.

97. Thorndike, E. L. The spread of the influence of reward to connections irrelevant to the learner's purposes. J. genet. Psychol., 1934, 44, 428-435.

98. * Tsuji, S. The function of "vector of situation" in memory. Jap. J. Psychol., 1935, 10, 567-600.

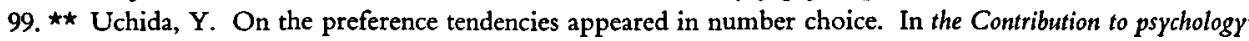
in memorium to Prof. Masuda., 1935, 215-227.

100. * Umemoto, T. Retroactive inhibition and formation of region. Psukhe, 1948, 4, 23-32.

101. * Umemoto, T. Association values of 1016 Japanese nonsense syllables. Jap. J. Psychol., 1951, 21, No.2, 23-28.

102. * Umemoto, T. The relative weight of stimulus versus response words in rote learing. Jap. J. Psychol., 1951, 21, No.3, 4, 46-55.

103. * Umemoto, T., Morikawa, Y. \& Ibuki, M. Similarity and familiarity scales of Japanese adjectives. Kyoto Univ. Res. Stud. Educ. 1955, 1, 85-116.

104. * Umemoto, T., Morikawa, Y. \& Ibuki, M. The non-association values and meaningfulness of 1892 Japanese two-letter syllables and words. Jap. J. Psychol., 1955, 26, 148-155.

105. * Umemoto, T. Similarity problems in verbal learning. J. philos. Stud., 1956, 38, 465-492.

106. $\star \star$ Umemoto, T. Similarity between sitmulus and response words in paired associate learning. Tohoku J. exp. Psychol., 1958, 2, 95-101.

107. Underwood, B. J. Associative transfer in verbal learning as a function of response similarity and degree of first list learning. J. exp. Psychol., 1951, 42, 44-53.

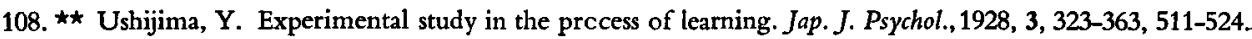

109. * Watanabe, T. Similarity problems in the transfer of learning. Okayama Univ. Res. Stud. 1958, No.9.

100. Wulf, F. Uber die Veranderung von Vorstellungen (Gedachtnis und Gestalt). Psychol. Forsch., 1922, 1, 333-373.

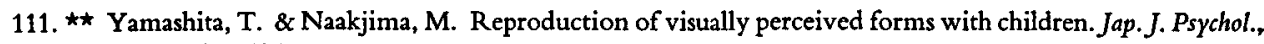
1930, 5, 476-486.

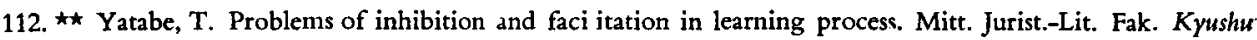
Univ. 1935. 279-360.

113. * Yokoyama, M. \& Yokoyama, E. The effect of stress on the recall of completed and interrupted taskes. Jap. J. educ. Psychol., 1954, 2, 157-161.

114. * Yoshimi, Y. The isolation effect between Japanese nonsense syllables. Jap. J. Psychol., 1953, 24, $246-247$.

115. Zirkle, G. A. Success and failure in serial learning. II. Isolation and the Thorndike effect. J. exp. Psychol., 1946, 36, 302-315.

Supplementary reference

116. Noble, C. E. An analysis of meaning. Psychol. Rev., 1952, 59, 421-430.

117. Osgood, C. E. and Suci, G. J., and Tannenbaum, P. H. The measurement of meaning. 1957.

118. Stone, G. R. The effect of negative incentives in serial learning. II. Incentive intensity and response variability. J. gen. Psychol., 1950, 42, 179-224.

119. Postman, L., Adams, P.A., \& Phillips, L. W. Studies in incidental learning:II. The effects of association value and of the method of testing. J. exp. Psychol., 1955, 49, 1-10.

* Articles written in Japanese with English summary.

$\star \star$ Articles written in Japanese.

MS. received II 11. 59.

Takao Umemoto (梅本筤夫, 1921- ）, graduated from Kyoto Univ. in 1948. Research fellow; 1948-1952, Lecturer; 1952-1955, Assistant Professor, Kyoto Univ.; Publications-Books: $N$-X intelligence test, with Osaka et al. 1957, Makino-shobo. Articles: Psychology of music. 1957. Nakayama-shoten. Learning aptitude. 1957. Nakayama-shoten. Psychological studies on learning of school subjects: I, II. with Kuraishi et al. 1959. Comparative study of response and attitude of American and Japanese children in number situation. 1959. in press. with G.M. Haslerud. Special interests: verbal learning, thinking, learning of school subjects, intelligence test, study of commercial message, psychology of music. 